\title{
KARAKTERISTIK AKSEPTOR KONTRASEPSI HORMONAL DAN HUBUNGAN PENINGKATAN BERAT BADAN DENGAN LAMA PENGGUNAANNYA DI PUSKESMAS KOTA JUANG KABUPATEN BIREUEN TAHUN 2020
}

\section{CHARACTERISTICS OF HORMONAL CONTRACEPTION ACCEPTORS AND THE RELATIONSHIP OF INCREASING WEIGHT WITH THE DURATION OF USE IN PUSKESMAS, JUANG CITY 2020}

Yolla Asmaul Nufra* ${ }^{* 1}$, Durratul Munawwarah ${ }^{2}$

1. Dosen Akbid Munawarah, Jl. Sultan Iskandar Muda No. 18 Kota Juang, Bireuen 24251, Indonesia

2. Mahasiswa Akbid Munawarah, Jl. Sultan Iskandar Muda No. 18 Kota Juang, Bireuen 24251, Indonesia

*Korespondensi Penulis : yollaasmaulnufra22@gmail.com*1 Durratul Munawwarah12@gmail.com*2

\begin{abstract}
Abstrak
Indonesia memiliki angka pertumbuhan penduduk yang tinggi, sehingga pemerintah melakukan upaya untuk mengurangi jumlah penduduk tersebut dengan kontrasepsi namun penggunaan kontrasepsi memiliki efek samping diantaranya perubahan kenaikan berat badan ini dapat dipengaruhi oleh berbagai faktor seperti faktor hormonal yang terkandung dalam KB Hormonal yaitu hormon estrogen dan progesteron. Penelitian ini bertujuan untuk mengetahui karakteristik akseptor kontrasepsi hormonal dan hubungan peningkatan berat badan dengan lama penggunaannya.

Penelitian ini menggunakan metode deskriptif analitik dengan pendekatan cross sectional, dimulai Agustus 2020 di Puskesmas Kota Juang Kabupaten Bireuen Tahun 2020. Jumlah sampel dalam penelitian ini 95 responden pengguna kontrasepsi hormonal. Analisis data menggunakan uji Chi Square

Hasil penelitian menunjukkan ada hubungan peningkatan berat badan dengan lama penggunaannya nilai p-value $<0.05$. Karakteristik IMT paling tinggi pada kategori Normal 55 responden $(57,9 \%)$. Umur paling tinggi kategori $\geq 35$ Tahun $52(54,7 \%)$. Paritas responden paling tinggi pada kategori multipara $58(61,1 \%)$. Pendidikan responden paling tinggi pada kategori multipara 58 (61,1\%). Pekerjaan responden paling tinggi pada kategori pendidikan menengah 46 $(61,1 \%)$. Jenis Kontrasepsi responden paling tinggi pada kategori suntik 63 $(61,1 \%)$. Hasil penelitian nilai Chi Square $\mathrm{p}=0.00$ yang menunjukan bahwa $\mathrm{Ha}$ di terima dan Ho ditolak yang artinya terdapat hubungan yang signifikan antara kenaiakan berat badan dengan lama pemakaian kontrasepsi hormonal.

Bagi Peneliti selanjutnya,di harapkan dapat digunakan sebagai dasar untuk penelitian selanjutnya namundengan menambahkan Karakteristik dan variabel lain yang belum di teliti.

Kata Kunci : Kontrasepsi hormonal, Berat badan, Lama pemakaian Kontrasepsi
\end{abstract}


Journal of Healthcare Technology and Medicine Vol. 6 No. 2 Oktober 2020

Universitas Ubudiyah Indonesia

e-ISSN : 2615-109X

\begin{abstract}
Indonesia has a high population growth rate, so the government made an effort to reduce the population with contraception but the use of contraception has side effects including changes in weight gain that can be influenced by various factors such as hormonal factors contained in hormonal contraceptives namely estrogen and progesterone. This study aims to determine the characteristics of hormonal contraceptive acceptors and the relationship between weight gain and length of use.

This research uses descriptive analytic method with cross sectional approach, starting Agustus 2020 at Kota Juang Health Center, Bireuen City. The number of samples in this study were 95 respondents using hormonal contraception.

Data analysis used Chi Square test with p-value <0.05. The characteristics of BMI were highest in the Normal category of 55 respondents (57.9\%). The highest age category is $\geq 35$ years $52(54.7 \%)$. The highest parity of respondents was in the multipara category 58 (61.1\%). The highest respondent education was in the multipara category 58 (61.1\%). The highest respondent occupation was in the secondary education category 46 (61.1\%). The highest type of respondent contraception in the injection category was 63 (61.1\%). The results of the Chi Square value of $p=0.00$ which shows that $\mathrm{Ha}$ is accepted and Ho is rejected, which means there is a significant relationship between weight wear and the length of hormonal contraceptive use.

For future researchers, it is hoped that it can be used as a basis for further research but by adding characteristics and other variables that have not been studied
\end{abstract}

Keywords: Hormonal contraception, body weight, duration of use of contraception

\title{
PENDAHULUAN
}

Jumlah penduduk Indonesia selama dua puluh lima tahun mendatang akan terus meningkat dari 238,5 juta pada tahun 2010 menjadi 305,6 juta pada tahun 2035, walaupun laju pertumbuhan rata-rata penduduk Indonesia selama periode 2010-2035 terus menurun dari 1,38 persen menjadi 0,62 persen pertahun. Sekitar 386.000 bayi lahir pada tanggal 1 januari 2018, dan lebih dari 90 persen lahir pada negara berkembang. Secara global, lebih dari separuh kelahiran ini diperkirakan terjadi disembilan negara. Indonesia menyumbang 13.370 kelahiran bayi dan berada di peringkat kelima setelah India, China, Nigeria, dan Pakistan dengan masing-masing menyumbang 69.070, 44.760, 20.210, 14.910 kelahiran bayi.

Undang-undang Nomor 52 tahun 2009 pasal 1 tentang perkembangan kependudukan dan pembangunan keluarga menyatakan bahwa Keluarga Berencana (KB) merupakan upaya dalam mengatur kelahiran anak, jarak, usia ideal melahirkan, mengatur kehamilan, melalui promosi, perlindungan, dan bantuan sesuai hak reproduksi untuk mewujudkan keluarga yang berkualitas. Dukungan manajemen pelayanan KB sangat penting, baik perencanaan, pelaksanaan, pemantauan sampai dengan evaluasi dalam rangka penguatan dan pencapaian tujuan pelayanan KB. Program KB memiliki dua kementerian/lembaga yang memegang 
Journal of Healthcare Technology and Medicine Vol. 6 No. 2 Oktober 2020

Universitas Ubudiyah Indonesia

e-ISSN : 2615-109X

peranan penting yaitu Kementerian Kesehatan dan Badan Kependudukan dan Keluarga Berencana Nasional (BKKBN).

World Health Organization (WHO) menyatakan bahwa penggunaan kontrasepsi telah meningkat di berbagai negara, terutama Asia dan Amerika Latin dan terendah di sub-sahara Afrika. Penggunaan kontrasepsi modern telah meningkat signifikan dari 54\% pada tahun 2014 menjadi 57,4\% pada tahun 2015. Secara ragional porposi pasangan usia subur 15-49 tahun, pengguna metode kontrasepsi modern telah meningkat minimal 6 tahun terakhir. Di Asia telah meningkat dari $60.9 \%$ menjadi $61.6 \%$, di Afrika dari 23,6\% menjadi 27.6\%, sedangkan Amerika Latin dan Karibia naik sedikit dari $66.7 \%$ menjadi 67.0\%.

Pada tahun 2015, di Indonesia tercatat jumlah Pasangan Usia Subur (PUS) sebanyak 36.684.599 jiwa dan terdaftar sebagai peserta KB aktif sebanyak 23.188.809 jiwa dengan pemakaian alat kontrasepsi dalam Rahim (AKDR) 2.007.592 jiwa, medis operatif pria (MOP) 172.887 jiwa, medis operatif wanita (MOW) 778.319 jiwa, implant 1.933 .869 jiwa, suntik 18.711.263 jiwa, pil 5.224.067 jiwa, dan kondom 369.105 jiwa.

Pengguna KB aktif di provinsi Aceh terus meningkat setiap bulannya. Jumlah PUS di wilayah Aceh pada akhir Desember 2017 yang tercatat mencapai 72.948 jiwa, dari jumlah tersebut yang menggunakan KB aktif mencapai 49.907 jiwa dengan pemakaian AKDR 1.148 jiwa, MOP 74 jiwa, MOW 231 jiwa, implan 1.101 jiwa, suntik 39.005 jiwa, pil 7.909 jiwa, dan kondom 439 jiwa. Jumlah PUS di Bireuen pada akhir Desember 2017 yang tercatat mencapai 8.784 jiwa, dari jumlah tersebut yang menggunakan KB aktif mencapai 6.414 jiwa dengan pemakaian AKDR 148 jiwa, MOP 6 jiwa, MOW 16 jiwa, implan 87 jiwa, suntik 5.270 jiwa, pil 849 jiwa, dan kondom 38 jiwa.

Pengguna KB aktif di Bireuen pada tahun 2019 terbanyak tercatat pada Puskesmas Kota Juang yaitu 7.196 orang dengan pemakaian kontrasepsi kondom 1.234 orang, pil 2.293 orang, suntik 3.132 orang, AKDR 447 orang, Implan 72 orang, MOW 16 orang, dan MOP 2 orang. Data di atas menunjukkan bahwa penggunaan metode kontrasepsi hormonal menduduki peringkat pertama pilihan akseptor KB dibandingkan metode kontrasepsi lainnya. Kontrasepsi hormonal merupakan salah satu alat/cara kontraepsi dengan penggunaan hormonal pada dasarnya dibagi menjadi 2 yaitu kombinasi (mengandung hormon progesteron dan estrogen) dan yang hanya berisi progesteron saja. Kontrasepsi hormonal kombinasi terdapat pada pil dan suntikan/injeksi. Sedangkan kontrasepsi hormone yang berisi progesteron terdapat pada pil, suntik, implant dan AKDR mirena. 
Journal of Healthcare Technology and Medicine Vol. 6 No. 2 Oktober 2020

Universitas Ubudiyah Indonesia

e-ISSN : 2615-109X

Namun penggunaan kontrasepsi hormonal ini dapat menimbulkan efek samping salah satunya berupa peningkatan berat badanyang memiliki hubungan dengan jangka waktu penggunaan kontrasepsi hormonal. Peningkatan berat badan adalah efek samping yang paling umum dirasakan dan alasan utama untuk penghentian penggunaan kontrasepsi. Peningkatan berat badan yang signifikan terlihat pada tahun pertama penggunaan kontrasepsi hormonal, dengan rata-rata pertambahan 2 kilogram $(\mathrm{kg})$ per tahunnya. Terdapat perbedaan peningkatan berat badan pada akseptor kontrasepsi suntik dengan kenaikan berat badan rata-rata $6,2 \mathrm{~kg}$ dibandingkan akseptor kontrasepsipil oral kombinasi dengan kenaikan berat badan rata-rata 2,3 kg selama 4-5 tahun penggunaan.

Peningkatan berat badan yang tidak terkontrol ini merupakan sesuatu yang dikhawatirkan akseptor karena akan mengakibatkan postur tubuh tidak proporsional, sehingga peniliti tertarik untuk melakukan penelitian tentang karakteristik akseptor kontrasepsi hormonal dan hubungan peningkatan berat badan dengan lama penggunaannya di Puskesmas Banda Sakti Kota Lhokseumawe.

\section{METODE PENELITIAN}

Desain penelitian yang digunakan adalah penelitian analitik dengan pendekatan cross sectional, yaitu penelitian yang dilakukan dengan tujuan utama untuk membuat gambaran tentang suatu keadaan secara objektif, dimana data yang menyangkut data bebas (resiko) dan variabel terikat (akibat), akan dikumpulkan dalam waktu yang sama (Iman, 2016).

Lokasi penelitian adalah tempat dimana penelitian dilaksanakan (Iman, 2016). Penelitian ini dilakukan di Puskesmas Kota Juang Kabupaten Bireuen Tahun 2020. Populasi adalah Jumlah dari keseluruhan dari satuan-satuan atau individu yang berkarakteristik hendak diteliti (Iman, 2016). Penelitian ini dilaksanakan pada Agustus 2020 Populasi dalam penelitian ini adalah yang terdiri dari 7.048 pengguna lama dan 148 pengguna baru di Puskesmas Kota Juang Kabupaten Bireuen. Sampel dalam penelitian ini Sampel dalam penelitian ini adalah akseptor kontrasepsi hormonal di Puskesmas Kota Juang Kabupaten Bireuen yang sesuai dengan kriteria inklusi dan eksklusi : Kriteria inklusi: Bersedia dijadikan sampel penelitian atau mendapatkan izin dari keluarga. Akseptor kontrasepsi pil, Suntik, Implant dan AKDR mirena (tidak menggunakan kontrasepsi yang lain) di Puskesmas Banda SaktiKota Lhokseumawe dan Kriteria eksklusi: Wanita dengan hipotiroid. Wanita yang mengkonsumsi obat-obat steroid, anti peradangan, anti depresan dan obat diabetes. Wanita yang mengalami penyakit serius 
Journal of Healthcare Technology and Medicine Vol. 6 No. 2 Oktober 2020

Universitas Ubudiyah Indonesia

e-ISSN : 2615-109X

seperti kista ovarium, penyakit ginjal, penyakit jantung, gangguan hati, diabetes maupun penyakit degeneratif lainnya.

Jenis data yang di gunakan data primer dan data sekunder. Analisis data dilakukan secara deskriptif dengan melihat presentasi data yang terkumpul dan disajikan dalam bentuk melihat frekuensi, selanjutnya dicari besarnya presentasi untuk jawaban masing-masing responden dengan menggunakan teori dan kepustakaan yang ada sehingga dapat diambil suatu kesimpulan.

\section{HASIL PENELITIAN}

Analisis Univariat digunakan untuk mengetahui distribusi frekuensi tentang Karakteristik Akseptor Kontrasepsi Hormonal Dan Hubungan Peningkatan Berat Badan Dengan Lama Penggunaannya.

\section{A. Karakteristik Responden}

Tabel 1. Distribusi Frekuensi Berdasarkan Karakteristik Responden

\begin{tabular}{|c|c|c|c|}
\hline No & Karakteristik Responden & $\mathrm{n}$ & $\%$ \\
\hline \multirow[t]{5}{*}{1} & IMT & & \\
\hline & - $\quad<18.5$ (Underweight) & 4 & 4.2 \\
\hline & - $\quad$ 18.5-24.9 (Normal) & 55 & 57.9 \\
\hline & - 25-29.9 (Overweight) & 28 & 29.5 \\
\hline & $-\quad \geq 30$ (Obesitas) & 8 & 8.4 \\
\hline \multirow[t]{3}{*}{2} & Umur & & \\
\hline & - $\quad<35$ Tahun & 43 & 45.3 \\
\hline & - $\quad \geq 35$ Tahun & 52 & 54.7 \\
\hline \multirow[t]{5}{*}{3} & Paritas & & \\
\hline & - Nulipara & 0 & 0 \\
\hline & - Primipara & 13 & 13.7 \\
\hline & - Multipara & 58 & 61.1 \\
\hline & - Grande Multipara & 24 & 25.3 \\
\hline \multirow[t]{4}{*}{4} & Pendidikan & & \\
\hline & - Pendidikan Dasar & 35 & 36.8 \\
\hline & - Pendidikan Menengah & 46 & 48.4 \\
\hline & - Pendidikan Tinggi & 14 & 14.7 \\
\hline \multirow[t]{3}{*}{5} & Pekerjaan & & \\
\hline & - Bekerja & 10 & 10.5 \\
\hline & - Tidak Bekerja & 85 & 89.5 \\
\hline \multirow[t]{5}{*}{6} & Jenis Kontrasepsi & & \\
\hline & - Pil & 28 & 29.5 \\
\hline & - Suntik & 63 & 66.3 \\
\hline & - Implan & 4 & 4.2 \\
\hline & - AKDR Mirena & 0 & 0 \\
\hline
\end{tabular}


Berdasarkan tabel 1. menunjukkan karakteristik responden yang meliputi IMT, umur, paritas, pendidikan, pekerjaan, dan jenis kontrasepsi hormonal (pil, suntik, implant dan AKDR mirena) pada sampel yang berjumlah 95 orang di Puskesmas Kota Juang Kabupaten Bireuen Tahun 2020. Kategori IMT pada responden paling tinggi berada pada kategori 18.524.9 (Normal) yaitu 55 orang $(57,9 \%)$ dan paling sedikit berada pada kategori <18.5 (Underweight) yaitu 4 orang $(4.2 \%)$. Kelompok umur terbanyak adalah $\geq 35$ tahun dengan jumlah responden 52 orang $(54.7 \%)$ dan kelompok umur $<35$ tahun berjumlah 43 orang $(45,3 \%)$. Paritas responden paling tinggi pada multipara sebanyak 58 orang $(61.1 \%)$ dan terendah pada paritas nulipara dengan tidak ada responden. Pendidikan responden tertinggi pada tingkat pendidikan menengah yaitu 46 orang $(48.4 \%)$ dan terendah pada tingkat pendidikan tinggi yaitu 14 orang (14.7\%). Kategori pekerjaan paling tinggi pada tidak bekerja yaitu 85 orang $(89.5 \%)$ dan yang bekerja 10 orang (10,5\%). Jenis kontrasepsi paling banyak yaitu suntik sebanyak 63 orang (66.3\%) dan paling sedikit yaitu AKDR mirena dengan tidak ada responden.

\section{B. Distribusi Frekuensi Berdasarkan Peningkatan Berat Badan}

Tabel 2 Distribusi Frekuensi Berdasarkan Peningkatan Berat Badan

\begin{tabular}{llcc}
\hline No & $\begin{array}{l}\text { Peningkatan } \\
\text { Berat Badan }\end{array}$ & n & \% \\
\hline 1 & Ya & 46 & 48.4 \\
2 & Tidak & 49 & 51.6 \\
\hline & Jumlah & $\mathbf{9 5}$ & $\mathbf{1 0 0}$ \\
\hline
\end{tabular}

Sumber: Data Primer 2020

Tabel 2 menunjukkan responden yang mengalami peningkatan berat badan yaitu 46 orang (48.4\%) dan yang tidak mengalami peningkatan berat badan yaitu 49 orang (51.6\%).

\section{Distribusi Frekuensi Berdasarkan Lama Penggunaan Kontrasepsi}

Tabel 3 Distribusi Frekuensi Berdasarkan Lama Penggunaan Kontrasepsi

\begin{tabular}{llcc}
\hline No & Lama Penggunaan & n & \% \\
\hline 1 & 1 Tahun & 21 & 22.1 \\
2 & 2 Tahun & 23 & 24.2 \\
3 & $\geq 3$ Tahun & 51 & 53.7 \\
\hline & Jumlah & $\mathbf{9 5}$ & $\mathbf{1 0 0}$ \\
\hline
\end{tabular}

Sumber: Data Primer 2020

Tabel 3 menunjukkan responden yang telah menggunakan kontrasepsi hormonal selama 1 tahun yaitu 21 orang $(22.1 \%)$, sedangkan responden dengan masa penggunaan 2 tahun yaitu 
Journal of Healthcare Technology and Medicine Vol. 6 No. 2 Oktober 2020

Universitas Ubudiyah Indonesia

e-ISSN : 2615-109X

23 orang $(24.2 \%)$, dan responden yang telah menggunakan kontrasepsi lebih dari 2 tahun yaitu 51 orang $(53.7 \%)$.

\section{Hubungan Peningkatan Berat Badan Dengan Lama Penggunaan Kontrasepsi Hormonal}

Tabel 4 Hubungan variabel peningkatan berat badan dengan lama penggunaan kontrasepsi hormonal

\begin{tabular}{|c|c|c|c|c|c|c|c|c|}
\hline \multirow{3}{*}{ No } & \multirow{3}{*}{$\begin{array}{c}\text { Lama } \\
\text { penggunaan }\end{array}$} & \multicolumn{4}{|c|}{$\begin{array}{c}\text { Peningkatan Berat } \\
\text { Badan }\end{array}$} & \multirow{2}{*}{\multicolumn{2}{|c|}{ Jumlah }} & \multirow{3}{*}{$P$ Value } \\
\hline & & \multicolumn{2}{|c|}{ Ya } & \multicolumn{2}{|c|}{ Tidak } & & & \\
\hline & & $\mathbf{n}$ & $\%$ & $\mathbf{n}$ & $\%$ & $\mathbf{n}$ & $\%$ & \\
\hline 1 & 1 Tahun & 3 & 3.2 & 18 & 18.9 & 21 & 22.1 & \\
\hline 2 & 2 Tahun & 8 & 8.4 & 15 & 15.8 & 23 & 24.2 & 0.000 \\
\hline 3 & $\geq 3$ Tahun & 35 & 36.9 & 16 & 16.8 & 51 & 53.7 & \\
\hline & Jumlah & 46 & 48.5 & 49 & 51.5 & 95 & 100 & \\
\hline
\end{tabular}

Sumber: Data Primer 2020

Tabel 4. menunjukkan responden dengan penggunaan kontrasepsi terbanyak $\geq 3$ tahun yaitu 51 orang (53,7\%). Pada penelitian ini digunakan uji Pearson Chi-Square dengan hasil menunjjkan $\mathrm{p}$ value sebebsar $0,000(\mathrm{p}<0,05)$ yang berarti Ha diterima sehingga dapat disimpulkan bahwa ada pengaruh/hubungan yang nyata antara lama penggunaan dengan peningkatan berat badan pada akseptor kontrasepsi hormonal di Puskesmas Banda Sakti Lhokseumawe.

\section{PEMBAHASAN}

Karakteristik Akseptor Kontrasepsi Hormonal dan hubungan Hubungan Peningkatan Berat Badan Dengan Lama Penggunaannya di Puskesmas Kota Juang Kabupaten Bireuen Tahun 2020: Penelitian Ini menunjukan hasil karakteristik responden yang meliputi IMT, umur, paritas, pendidikan, pekerjaan, dan jenis kontrasepsi hormonal (pil, suntik, implant dan AKDR mirena) pada sampel yang berjumlah 95 orang di Puskesmas Banda Sakti Kota Lhokseumawe Tahun 2020. Kategori IMT pada responden paling tinggi berada pada kategori 18.5-24.9 (Normal) yaitu 55 orang (57,9\%) dan paling sedikit berada pada kategori <18.5 (Underweight) yaitu 4 orang (4.2\%). Kelompok umur terbanyak adalah $\geq 35$ tahun dengan jumlah responden 52 orang (54.7\%) dan kelompok umur <35 tahun berjumlah 43 orang $(45,3 \%)$. Paritas responden paling tinggi pada multipara sebanyak 58 orang $(61.1 \%)$ dan terendah pada paritas nulipara dengan tidak ada responden. Pendidikan responden tertinggi pada tingkat pendidikan menengah yaitu 46 orang (48.4\%) dan terendah 
Journal of Healthcare Technology and Medicine Vol. 6 No. 2 Oktober 2020

Universitas Ubudiyah Indonesia

e-ISSN : 2615-109X

pada tingkat pendidikan tinggi yaitu 14 orang (14.7\%). Kategori pekerjaan paling tinggi pada tidak bekerja yaitu 85 orang $(89.5 \%)$ dan yang bekerja 10 orang (10,5\%). Jenis kontrasepsi paling banyak yaitu suntik sebanyak 63 orang (66.3\%) dan paling sedikit yaitu AKDR mirena dengan tidak ada responden.

Hasil distribusi frekuensi berdasarkan peningkatan berat badan menunjukkan responden yang mengalami peningkatan berat badan yaitu 46 orang $(48.4 \%)$ dan yang tidak mengalami peningkatan berat badan yaitu 49 orang (51.6\%). Distribusi frekuensi berdasarkan lama penggunaan kontrasepsi menunjukkan responden yang telah menggunakan kontrasepsi hormonal selama 1 tahun yaitu 21 orang (22.1\%), sedangkan responden dengan masa penggunaan 2 tahun yaitu 23 orang (24.2\%), dan responden yang telah menggunakan kontrasepsi lebih dari 2 tahun yaitu 51 orang (53.7\%).

Berdasarkan hasil analisa statistik menggunakan uji chi square, dengan peningkatan berat badan dengan penggunaan kontrasepsi hormonal tingkat kepercayaan 95\%( $\alpha=0,05)$ di dapat nilai $\mathrm{p}$ value $(0,000)<\alpha(0,05)$ sehingga didapatkan hasil penelitian bahwa ada hubungan peningkatan berat badan dengan penggunaan kontrasepsi hormonal di Puskesmas Kota Juang Kabupaten Bireuen Tahun 2020. Hasil peneilitan ini sejalan dengan penelitian Widianti dkk pada tahun 2010 yang menunjukkan terdapat hubungan yang signifikan antara lama pemakaian kontrasepsi dengan peningkatan berat badan akseptor. Hasil penelitian ini juga sejalan dengan penelitian Irawati pada tahun 2017 yang menunjukkan terdapat pengaruh yang signifikan lama penggunaan kontrasepsi terhadap kenaikan berat badan. Hasil penelitian yang didapatkan juga sejalan dengan penelitian Moloku dkk pada tahun 2016 yang menunjukkan terdapat hubungan yang signifikan antara lama pemakaian kontrasepsi dengan perubahan berat badan.

Peningkatan berat badan pada akseptor kontrasepsi hormonal akibat dari hormon progesteron yang merangsang pusat pengendali nafsu makan dihipotalamus menyebabkan nafsu makan meningkat dari pada biasanya. Adanya nafsu makan yang lebih banyak dari biasanya tubuh akan kelebihan zat-zat gizi. Kelebihan zat-zat gizi oleh hormon progesteron akan dirubah menjadi lemak dan disimpan di bawah kulit, sehingga peningkatan berat badan ini terjadi akibat adanya penumpukan lemak berlebihan terus-menerus hasil sintesa dari karbohidrat dan glukosa menjadi lemak. Kontrasepsi hormonal dapat mengaktivasi hormon glukokortikoid reseptor dan dalam dosis yang tinggi dapat mengubah metabolism lemak, hal 
Journal of Healthcare Technology and Medicine Vol. 6 No. 2 Oktober 2020

Universitas Ubudiyah Indonesia

e-ISSN : 2615-109X

ini dapat menyebabkan terjadinya penumpukan lapisan lemak pada manusia yang secara otomatis meningkatkan berat badan.

Berdasarkan asumsi dari penulis, tidak semua akseptor akan mengalami kenaikan berat badan, karena efek dari hormon tersebut tidak selalu sama pada setiap individu dan juga dipengaruhi reaksi tubuh akseptor kontrasepsi tersebut terhadap metabolisme progesteron.(14)'(21) Penggunaan kontrasepsi hormonal memilik efektivitas berbeda, sehingga dapat menyebabkan peningkatan berat badan yang bervariasi.

\section{KESIMPULAN}

Kesimpulan peneliti ini ada Hubungan Peningkatan Berat Badan Dengan Lama Penggunaannya Di Puskesmas Kecamatan Banda Sakti Lhokseumawe diperoleh nilai $\mathrm{p}$ value $(0,000)<\alpha(0,05)$, maka Ha diterima Ho ditolak dan dapat disimpulkan bahwa ada hubungan Hubungan Peningkatan Berat Badan Dengan Lama Penggunaannya di wilayah kerja Puskesmas Jeumpa Kabupaten Bireuen Tahun 2020.

\section{SARAN}

Bagi Peneliti selanjutnya,di harapkan dapat digunakan sebagai dasar untuk penelitian selanjutnya namundengan menambahkan Karakteristik dan variabel lain yang belum di teliti.

Bagi Dinas Kesehatan Provinsi Aceh Khususnya Kepala Bidang Kesehatan Masyarakat yang membawahi Seksi Promosi dan Pemberdayaan Masyarakat khususnya agar dapat melakukan berbagai upaya, guna menggalakkan program Keluarga Berencana yang difokuskan melalui upaya penyuluhan kesehatan reproduksi.

\section{DAFTAR PUSTAKA}

Badan Pusat Statistik Indonesia. Proyeksi Penduduk Indonesia Indonesia Population Projection 2010-2035. Badan Pusat Statistik Indonesia. 2013. 978-979 p.

UNICEF. Nearly 386,000 children will be born worldwide on New Year's Day, says UNICEF. https://www.unicef.org/media/media_102362.html. 2018. p. 1.

Kementerian Kesehatan RI. Buletin Kespro. 2013;

Mahmudah LTN, Indrawati F. Analisis Faktor yang Berhubungan dengan pemilihan Metode Kontrasepsi Jangka Panjang (MKJP) pada Akseptor KB Wanita di Kecamatan Banyubiru Kabupaten Semarang. 2015;2(2):76-85.

Pradani NNW, Ulandari Y. Kontrasepsi KB Suntik di Puskesmas Gunung Samarinda Kota Balikpapan Tahun 2017. 2018;

BKKBN. FELISA. http://manajemenpk.bkkbn.go.id/felisa/default.aspx? 
ProvinsiID $=\&$ map $=\&$ Periode $=12 / 31 / 2015 \% 2012: 00: 00 \% 20 A M .2015$.
BKKBN. FELISA. ProvinsiID=1\&map=110000\&Periode=12/31/2016\%2012:00:00\%20AM. 2016.

Dinas Kesehatan Kota Lhokseumawe. Data pengguna KB 2018. Lhokseumawe; 2018.

Meilani N, Setiyawati N, Estiwidani D, Suherni. Pelayanan Keluarga Berencana. Yogyakarta: Fitramaya; 2012.

Liando H, Kundre R, Bataha Y. Faktor-Faktor yang Berhubungan dengan Peningkatan Berat Badan Ibu Pengguna Alata Kontrasepsi Suntik DMPA di Puskesmas Kumelembu AI Kabupaten Minahasa Selatan. e-Journal Keperawatan. 2015;3:1-7.

Jacobstein R, Polis CB. Best Practice \& Research Clinical Obstetrics and Gynaecology Progestin-only contraception: Injectables and implants. Best Pract Res Clin Obstet Gynaecol. 2014;28(6):795-806.

Mulyani NS, Rinawati M. Keluarga Berencana dan Alat Kontrasepsi. Yogyakarta: Nuha Medika; 2013.

Wiknjosastro H. Ilmu Kebidanan. Jakarta: Yayasan Bina Pustaka Sarwono Prawirohardjo; 2009.

Hartanto H. Keluarga Berencana dan Kontrasepsi. Jakarta: Pustaka Sinar Harapan; 2010.

Everett S. Kontrasepsi \& Kesehatan Seksual Reproduktif. Jakarta: EGC; 2013.

Arum DNS, Sujiyatini. Panduan Lengkap Pelayanan KB Terkini. Yogyakarta: Nuha Medika; 2011.

Saifuddin AB, Affandi B, Enriquito. Buku Panduan Praktis Pelayanan Kontrasepsi. Jakarta: Yayasan Bina Pustaka Sarwono Prawirohardjo; 2014.

Soetjiningsih. Tumbuh Kembang Anak. 2nd ed. Jakarta: EGC; 2015.

Syoergawi BM. Konstribusi Berat Badan dan Kelincahan Terhadap Kemampuan Dribble Dalam Permainan Bola Basket Pada Siswa Ekstrakulikuler Bola Basket SMAN 1 Bengkulu Selatan. 2014;

Rosmiati. Perbedaan Peningkatan Berat Badan Antara Akseptor KB Suntik 1 Bulan (Cyclofem) dengan Akseptor KB Suntik 3 Bulan (Depo Medroksi Progesteron Asetat/DMPA) di Polindes Huko-Huko Kecamatan Pomala Kabupaten Kolaka. 2018;

Kamariah N. Pemakaian Kontrasepsi Suntik Akan Mempengaruhi Berat Badan Akseptor KB Suntik di Kota Baru Driyorejo. 2014;

Lopez LM, Ramesh S, Chen M, Edelman A, Otterness C, Trussell J, et al. Progestin-only contraceptives: effects on weight. 2016;

E. Beksinska M, A. Smit J, Kleinschmidt I, Milford C, M. M. Farley T. Prospective study of weight change in new adolescent users of DMPA, NET-EN, COCs, nonusers and discontinuers of hormonal contraception. 2010;

Fatati A. Korelasi antara Tinggi Badan dan Panjang Jari Tangan. 2014;

Wulan AJ, W ID. Korelasi Antara Panjang Tulang Radius Dengan Tinggi Badan Pada Pria Dewasa Suku Lampung dan Suku Jawa di Kecamatan Gisting Kabupaten Tanggamus. 2018;

Sutriani KT. Perbedaan Antara Tinggi Badan Berdasarkan Panjang Ulna Dengan Tinggi Badan Aktual Dewasa Muda Di Kota Semarang. 2014;

World Health Organization. Body mass index - BMI.

Habut MY, Nurmawan IPS, Wiryanthini IAD. Hubungan Indeks Massa Tubuh dan Aktivitas Fisik Terhadap Keseimbangan Dinamis Pada Mahasiswa Fakultas Kedokteran Universitas Udayana. 2015;

Dien NG, Mulyadi, Kundre RM. Hubungan Indeks Massa Tubuh (IMT) Dengan Tekanan Darah Pada Penderita Hipertensi Di Poliklinik Hipertensi Dan Nefrologi BLU RSUP 
Prof. DR. R. D. Kandou Manado. 2014;

Rohmatin N. Hubungan Antara Umur dan Lama Penggunaan Terhadap Keluhan Kesehatan pada Wanita Usia Subur Pengguna Alat Kontrasepsi Honnonal dan Non-hormonal di Pulau Jawa Tahun 2012. 2015;

Pratiwi D, Syahredi, Erkadius. Hubungan Antara Penggunaan Kontrasepsi Hormonal Suntik DMPA dengan Peningkatan Berat Badan di Puskesmas Lapai Kota Padang. 2014;3(3):365-9.

Rizkianti A, Amaliah N, Rachmalina R. Penggunaan Kontrasepsi pada Remaja Perempuan Kawin di Indonesia (Analisis Riskesdas 2013). 2017;

Finer LB, Philbin JM. Trends in Ages at Key Reproductive Transitions in the United States. 2014;

Winner B, Peipert JF, Zhao Q, Buckel C, Madden T, Allsworth JE, et al. Effectiveness of Long-Acting Reversible Contraception. 2012;

Wakerkwa B. Faktor-Faktor Yang Berhubungan Dengan Penggunaan Metode Kontrasepsi Implant Di Wilayah Kerja Puskesmas Teladan Kecamatan Medan Kota Tahun 2017. 2017

Kaporina M. Hubungan Paritas Terhadap Minat Penggunaan Alat Kontrasepsi di Puskesmas Banguntapan II Bantul Yogyakarta. 2016;

Yeni, Mutahar R, Etrawati F, Utama F. Paritas dan Peran Serta Suami Dalam Pengambilan Keputusan Terhadap Penggunaan Metode Kontrasepsi. 2017;

Pinontoan S, Solang SD, Tombokan SGJ. Faktor-Faktor Yang Berhubungan Dengan Penggunaan Alat Kontrasepsi Dalam Rahim Di Puskesmas Tatelu Kabupaten Minahasa Utara. 2014;

Wulandari Y, Ridha A, Taufik M. Faktor-Faktor Yang Mempengaruhi Penggunaan Metode Kontrasepsi JangkaPanjang (MKJP) Pada PasanganUsia Subur di Kabupaten Sambas. 2015;50.

Wahyuningsih N, Yuliaswati E, Rina. Karakteristik Akseptor Kontrasepsi Suntik DMPA di Desa Gringging, Sambungmacan, Sragen. 2015;

Fitri A. Hubungan Tingkat Pendidikan dan Penggunaan Alat Kontrasepsi Dengan Jumlah Anak yang Dilahirkan Wanita Pasangan Usia Subur (PUS) di Desa Pemanggilan Kecamatan Natar Kabupaten Lampung Selatan. 2016;

Sari AN, Sulistyorini E. Analisis Faktor yang mempengaruhi pemilihan Metode Kontrasepsi Jangka Panjang di Puskesmas Kartasura. 2017;

Astuti D, Ilyas H. Faktor-faktor yang berhubungan pemilihan alat kontrasepsi suntik. 2015;

Badan Pusat Statistik Idonesia. Pendidikan.

Budiarti I, Nuryani DD, Hidayat R. Determinan Penggunaan Metode Kontrasepsi Jangka Panjang ( MKJP ) pada Akseptor KB. 2017;

Yulidasari F, Lahdimawan A, Rosadi D. Hubungan Pengetahuan Ibu dan Pekerjaan Ibu dengan Pemilihan Kontrasepsi Suntik. 2015;

Setyarini DI. Lama Penggunaan Depo Medroksi Progesteron Asetat (Dmpa) Dan Indeks Massa Tubuh (IMT) Akseptor Kontrasepsi Suntik. J Inf Kesehat Indones. 2015;1(1):8-16.

Varney. Buku Saku Bidan. Jakarta: EGC; 2011.

Salvina, Hasifah SS. Faktor-Faktor Yang Mempengaruhi Rendahnya Minat Untuk Menggunakan Metode Kontrasepsi Hormonal ( Implant ) Pada Akseptor $\mathrm{Kb} \mathrm{Di}$ Puskesmas Kassi-Kassi Makassar. J e-library Stikes Nani Hasanudin Makasar. 2013;2(4):1-10.

Widianti AD, Hidayat A, Ismawarti. Hubungan Lama Pemakaian dengan Peningkatan Berat 
Journal of Healthcare Technology and Medicine Vol. 6 No. 2 Oktober 2020

Universitas Ubudiyah Indonesia

e-ISSN : 2615-109X

badan Pada Akseptor KB Suntik DMPA di BPS Pipin Bantul Yogyakarta Tahun 2008. 2010;

Irawati A. Pengaruh Kontrasepsi Suntik Terhadap Peningkatan Berat Badan Dengan Lamanya Penggunaan Pada Akseptor Keluarga Berencana Di Puskesmas Lompoe Kota Parepare Tahun 2017. 2017;(17).

Moloku M, Hutagaol E, Masi G. Hubungan Lama Pemakaian Lama Kontrasepsi Suntik 3 Bulan Dengan Perubahan Berat Badan Di Puskesmas 